\title{
Risk Factors Associated with Diabetes Mellitus in Local Population of Lahore, Pakistan
}

\author{
Sana Arshad ${ }^{1}$, Sania Tahir ${ }^{2}$, Bilal Tahir ${ }^{2}$, Nazia Tahir ${ }^{3}$, Tahir Rasool ${ }^{4}$, Salman Munir ${ }^{1}$, \\ Ataul Mustafa ${ }^{1} \&$ Kashaf Junaid ${ }^{1}$ \\ ${ }^{1}$ University Institute of Medical Laboratory Technology, University of Lahore, Pakistan \\ ${ }^{2}$ Jinnah Hospital, Lahore, Pakistan \\ ${ }^{3}$ General Hospital, Lahore, Pakistan \\ ${ }^{4}$ Akhuwat Health Services and Diabetes Centre, Lahore, Pakistan \\ Correspondence: Dr. Kashaf Junaid, University Institute of Medical Laboratory Technology, University of Lahore, \\ Pakistan. Tel: 92345-412-8191.
}

Received: May 16, 2017 Accepted: June 6, 2017 Online Published: June 19, 2017

doi:10.5539/gjhs.v9n9p42 URL: https://doi.org/10.5539/gjhs.v9n9p42

\begin{abstract}
Background: Diabetes is the leading cause of morbidity and mortality amongst the people of Pakistan. In 2015, 7 million people had diabetes and the number is still on raise. Family history of diabetes, high body mass index, and other sociodemographic factors are the risk factors of diabetes. Persistent exposure to excessive glucose may be a reason behind diabetic complications like nephropathy, neuropathy, retinopathy, cardiomyopathy and gestational diabetes mellitus.
\end{abstract}

Methods: For the evaluation of laboratory parameters, 600 blood samples were collected at Akhuwat Diabetic Centre and from Jinnah Hospital, Lahore. Demographic data of the participants was collected by filling a questionnaire. Lipid profile, liver enzymes, and renal function tests were performed and statistical analysis was done.

Results: Type 2 diabetes mellitus among other types is the most prevalent form of diabetes in our population. Family history of diabetes $(\mathrm{p}=0.002)$, Body Mass Index $(>25) \mathrm{p}<0.001$, high cholesterol $(\mathrm{p}=0.04)$, high triglyceride $p<0.001$, high LDL $p<0.001$ and low HDL $p<0.001$ are significantly associated with the incidence of diabetes. Hypertension among the other comorbidities is more common in diabetic patients.

Conclusion: Type 2 Diabetes Mellitus is highly prevalent in the local population. Improved lifestyle and proper medical monitoring can help to manage diabetes in our population.

Keywords: T2DM, BMI, lipid profile, liver enzymes, renal profile

\section{Introduction}

Diabetes Mellitus a metabolic disorder arises if body is incapable to synthesize sufficient insulin for metabolism, it could be due to improper insulin secretion, improper insulin action, or both. Persistent exposure to excessive glucose could be a dominant reason for cardiomyopathies nephropathies, retinopathies, neuropathies and a variety of different sorts of tissue injury. Diabetes mellitus additionally leads to vascular disease, hypertension, dyslipidemia, and obesity (Leech et al., 2011; Malandrino, Wu, Taveira, Whitlatch, \& Smith, 2012; Zimmet, Magliano, Herman, \& Shaw, 2014) (Figure 1). 


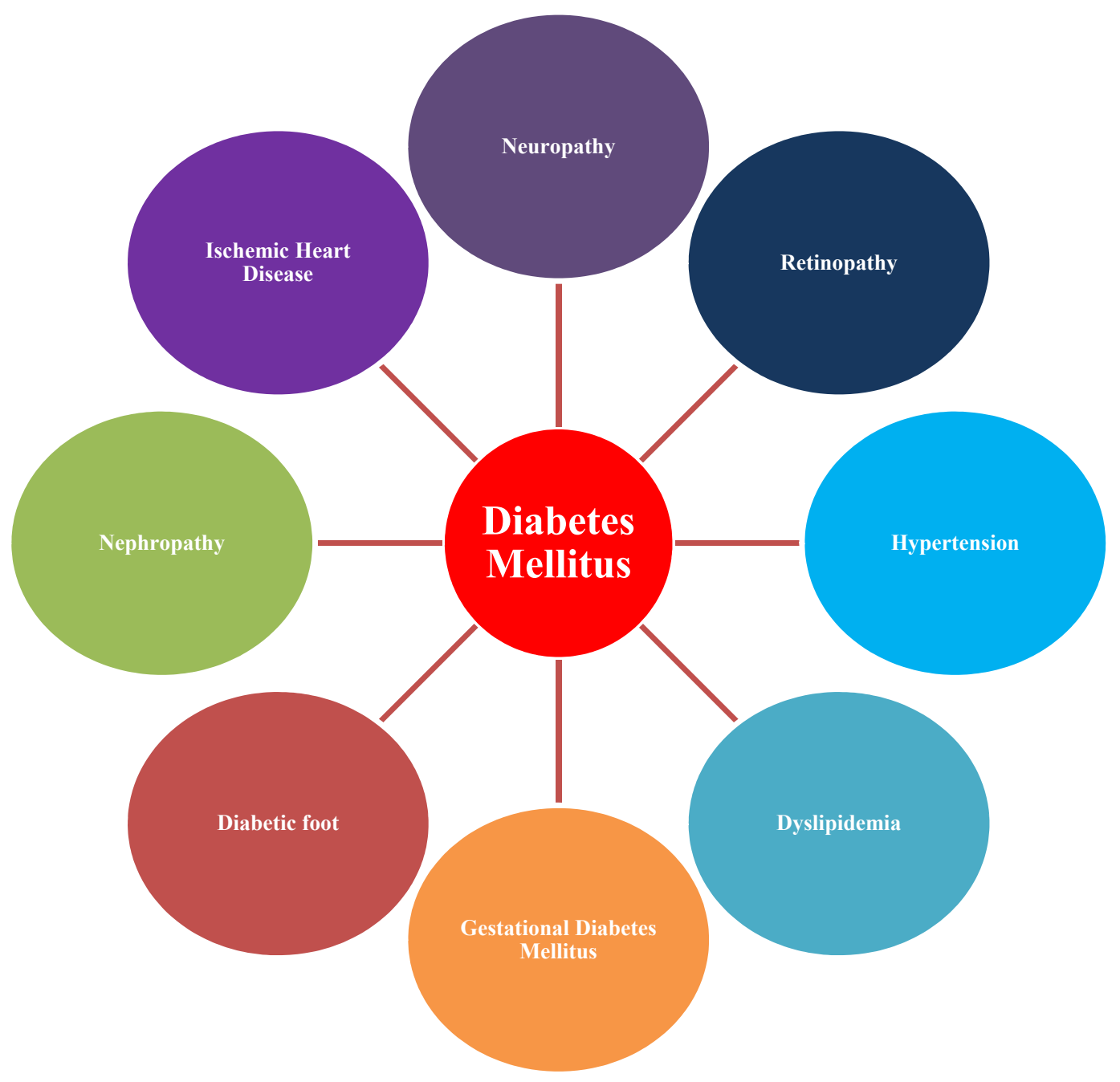

Figure 1: Diabetes-related complications

The most common type of diabetes is Type 2 (95\%), while Type 1 only contributes 4-5\% (Model, 2015; World Health, 2016). According to WHO in 2014, 422 million adults have diabetes worldwide (World Health, 2016). International Federation of Diabetes (IDF) reported that approximately 415 million people had diabetes in 2015 (IDF Diabetes Atlas, 2017) and almost 1.5 million deaths are directly attributed to diabetes each year (World Health, 2016). In Pakistan diabetes is one of the most prevalent metabolic disorder. In 2015, National Diabetes Action Plan of Pakistan reported over 7 million people suffering from diabetes (Sherin, 2015). According to International Diabetes Federation (IDF) report, the prevalence of diabetes in Pakistan in 2014 was approximately 7\% ("International Diabetes Federation ", 2015). A diagnostic criterion for the diagnosis of diabetes mellitus defined by World Health Organization (WHO) and International Diabetes Federation (IDF) is presented in figure 2 (IDF Diabetes Atlas, 2017). 


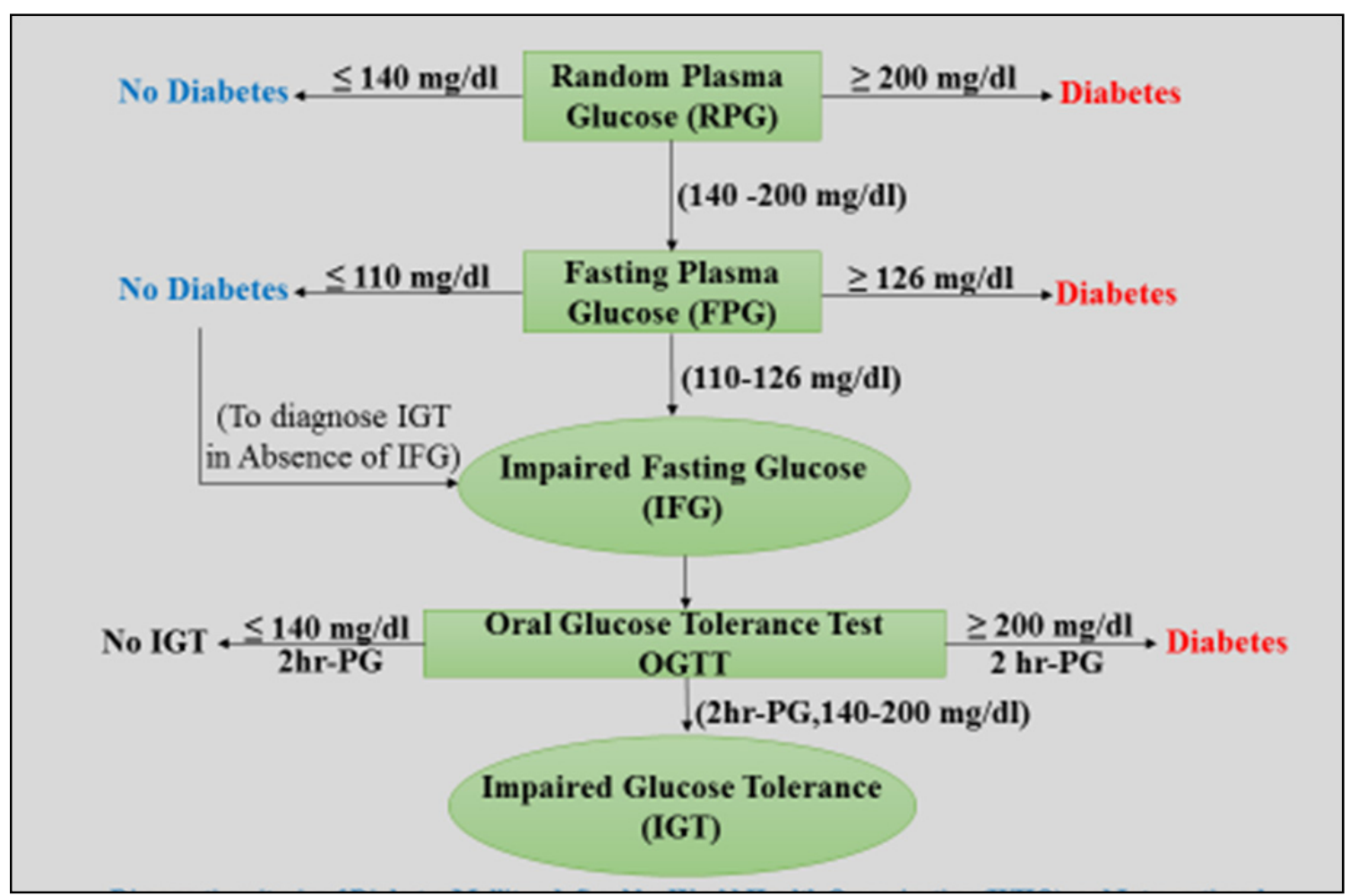

Figure 2. Diagnostic criteria of Diabetes Mellitus defined by World Health Organization (WHO) and International Federation of Diabetes (IFD)

Numerous studies on the prevalence and risk factors related to T2DM are disbursed in the Asian nation within the past, however, most of them are restrained to South Indian populations (Sethi, Kumar, Gupta, \& Bhanwer, 2011). So this study was conducted to compare social and demographic features among diabetic and non-diabetic individuals in our local population. Another important aim of this study was to compare lipid profile, renal function tests and liver function tests in diabetic and non-diabetic individuals.

\section{Materials and Methods}

\subsection{Study Design}

A cross-sectional study was designed, in which 600 blood samples were collected from the participants visited Akhuwat Diabetic Centre, Township Lahore, and Jinnah Hospital Lahore from December 2016 to April 2017.

\subsection{Sample Size}

According to International Diabetes Federation (IDF) report, the prevalence of diabetes in Pakistan in 2014 was approximately $7 \%$ so using open epi software a minimum sample size for this study was 101 with $95 \%$ confidence interval ("International Diabetes Federation ", 2015; Sherin, 2015).

\subsection{Sample Collection, Transportation, and Storage}

From all the subjects including in the study, $5 \mathrm{ml}$ blood was drawn from the median cubital vein of the arm with the help of sterilized 5cc syringe and collected in EDTA-containing tube, serum separating tube and sodium fluoride containing tube. Samples were carefully transported to Laboratory and stored at $2-8^{\circ} \mathrm{C}$ for further processes.

\subsection{Demographic Data}

Demographic data of the participants was collected by filling a questionnaire, including the following particulars: age, gender, smoking, alcohol consumption, family history of diabetes, family history of hypertension, surgical history of the participants and any other comorbidity. Body mass index (BMI) of the participants was calculated by the following formulae:

$$
\text { BMI }=\frac{\text { Weight of the person in Kgs }}{\text { Height of the person in } \mathrm{m}^{2}}
$$




\subsection{Laboratory Analysis}

\section{Blood Sugar Random (BSR)}

Blood Glucose of all participants was estimated by using kits of Cobas ${ }^{\circledR} \mathrm{c} 311$ by Roche Diagnostics, USA.

\section{HbA1c}

For all those participants who had elevated levels of Blood Glucose, estimation of blood glycated hemoglobin (HbA1c) was done (Cobas ${ }^{\circledR} \mathrm{c} 311$, Roche Diagnostics USA).

\section{Lipid Profile:}

Serum Cholesterol, Triglyceride, High Density Lipoprotein (HDL) and Low Density Lipoprotein (LDL) were measured in all blood samples (Cobas ${ }^{\circledR} \mathrm{c} 311$ by Roche Diagnostics USA).

\section{Renal Function Tests (RFTs)}

For renal function test Serum Urea, Serum Creatinine and Serum Uric Acid were measured and kits of Cobas ${ }^{\circledR}$ c311 by Roche Diagnostics USA were used.

\section{Liver Function Test (LFTs)}

Serum Total Bilirubin, Serum Alanine Aminotransferase (ALT), Serum Aspartate Aminotransferase (AST) and Serum Alkaline Phosphatase (ALP) were estimated by using kits of Cobas ${ }^{\circledR}$ c311 by Roche Diagnostics USA.

\subsection{Statistical Analysis}

Data was stored in Microsoft EXCEL and analyzed using the Statistical Package for Social Sciences (SPSS 21.0.verison). Descriptive analysis was done for the calculation of frequencies of different variables. Chi-square test was done to evaluate any significant association among qualitative variables and Independent T-test was done to compare mean difference between diabetic and non-diabetic group. Regression analysis was done to find out Odd Ratio (OR) and 95\% Confidence Interval (CI) for different variables. P value less than 0.05 was considered as significant in this study.

\section{Results}

In this cross sectional study, blood samples from 600 participants were collected, of which $83 \%$ were diabetic and only $17 \%$ were non diabetic. Table 1 presents the comparison of diabetic patients $v s$. non-diabetic group; of 500 diabetic patients $221(44 \%)$ were male and $279(56 \%)$ were females while $45 \%$ were non-diabetic males and 55\% were non-diabetic females. Results of chi-square analysis indicate diabetes is gender independent. Diabetes was more prevalent in married people as $99 \%$ of the diabetic patients were married ( $p$ value $<0.001$ ). Two-hundred and eighty-two $(56 \%)$ of diabetic patients with $>10,000$ PKR income were moderate while rest (44\%) were with the poor socioeconomic background ( $\leq 10,000$ PKR monthly income). Socio-economic status showed a borderline significant relation with the high prevalence of diabetes ( $\mathrm{p}$ value $=0.05$ ).

Smoking and Alcohol consumption did not show any statistical significance with diabetes. Results of this study indicate body mass index (BMI) was significantly associated with diabetes. Among 600 participants 362 were obese and $96 \%$ of these obese participants had diabetes ( $p$ value $<0.001$ ). 
Table 1. Comparison of Diabetic and Non-Diabetic Group

\begin{tabular}{lllll}
\hline Characteristics & & $\begin{array}{l}\text { Diabetic Group } \\
\mathrm{n}=500\end{array}$ & $\begin{array}{l}\text { Non-Diabetic Group } \\
\mathrm{n}=100\end{array}$ & p value \\
\hline \multirow{2}{*}{ Gender } & Male & $221(44 \%)$ & $45(45 \%)$ & 0.88 \\
& Female & $279(56 \%)$ & $55(55 \%)$ & \\
Marital Status & Married & $497(99 \%)$ & $82(82 \%)$ & $<0.001$ \\
& Unmarried & $3(1 \%)$ & $18(18 \%)$ & \\
Socio-economic Status & Poor & $218(44 \%)$ & $33(33 \%)$ & 0.05 \\
& Moderate & $282(56 \%)$ & $67(67 \%)$ & 0.28 \\
Smoking & Non-smoker & $457(91 \%)$ & $88(88 \%)$ & \\
& Smokers & $43(9 \%)$ & $12(12 \%)$ & 0.43 \\
\multirow{2}{*}{ BMI } & Non-alcohol Consumer & $498(99.6 \%)$ & $99(99 \%)$ & \\
& Alcohol Consumer & $2(0.4 \%)$ & $1(1 \%)$ & $<0.001$ \\
\hline
\end{tabular}

Out of 500 diabetic patients $96.8 \%$ had Type-2 Diabetes Mellitus and others had Type-1 Diabetes Mellitus. Glycated hemoglobin (HbA1c) was raised ( $>6.0 \%)$ in 464 (93\%) of the diabetic patients and only $36(7 \%)$ of the diabetic patients had their normal HbA1c (4.0-6.0\%).

Hypertension is highly prevalent in diabetic patients (45\%) among all other comorbidities (Table 2).

Table 2. Prevalence of Comorbidities in Diabetic Patients

\begin{tabular}{ll}
\hline Comorbidities & Frequency (Percentage) \\
\hline Hypertension (HTN) & $226(45 \%)$ \\
Surgical History & $180(36 \%)$ \\
Dyslipidemia & $39(8 \%)$ \\
Ischemic Heart Disease (IHD) & $32(6 \%)$ \\
Nephropathy & $26(5 \%)$ \\
Neuropathy & $22(4 \%)$ \\
Liver Disease & $17(3 \%)$ \\
Diabetic Foot & $5(1 \%)$ \\
Infectious Diseases & $3(0.6 \%)$ \\
Retinopathy & $2(0.4 \%)$ \\
\hline
\end{tabular}

Results indicate Lipid Profile (Serum Cholesterol, Triglyceride, HDL and LDL) was statistically associated with the incidence of diabetes mellitus. Serum Cholesterol (p value: 0.04; OR: 1.56; 95\% CI: 1.00-2.45), Serum Triglyceride (p value: $<0.001$; OR: 3.86; 95\% CI: 2.23-6.70), Serum HDL (p value: $<0.001$ OR: $3.24 ; 95 \%$ CI: 1.68-6.24) and Serum LDL (p value: $<0.001$; OR: 2.63; 95\% CI:1.43-3.89). Statistically Liver Function Tests (Serum Total Bilirubin, ALT, AST and ALP) and Renal Function Tests (Serum Urea, Creatinine and Uric Acid) did not show any association with diabetes mellitus (Table 3 ). 
Table 3. Comparison of Lab Parameters among Diabetic and Non-Diabetic Group

\begin{tabular}{|c|c|c|c|c|c|}
\hline \multicolumn{2}{|l|}{ Lab Parameter } & \multirow{2}{*}{$\begin{array}{l}\text { Diabetic Group } \\
n=500 \\
229(87 \%)\end{array}$} & \multirow{2}{*}{$\begin{array}{l}\text { Non-Diabetic Group } \\
n=100 \\
35(13 \%)\end{array}$} & \multirow{3}{*}{$\begin{array}{l}\text { OR }(95 \% \text { CI }) \\
1.56(1.00-2.45)\end{array}$} & \multirow{3}{*}{$\begin{array}{l}\text { p value } \\
0.04\end{array}$} \\
\hline \multirow[t]{2}{*}{ Cholesterol } & $\leq 200 \mathrm{mg} / \mathrm{dL}$ & & & & \\
\hline & $>200 \mathrm{mg} / \mathrm{dL}$ & $271(81 \%)$ & $65(19 \%)$ & & \\
\hline \multirow[t]{2}{*}{ Triglycerides } & $30-200 \mathrm{mg} / \mathrm{dL}$ & $279(77 \%)$ & $83(23 \%)$ & \multirow{2}{*}{$3.86(2.23-6.70)$} & \multirow{2}{*}{$<0.001$} \\
\hline & $>200 \mathrm{mg} / \mathrm{dL}$ & $221(93 \%)$ & $17(7 \%)$ & & \\
\hline \multirow[t]{2}{*}{ HDL } & $35-65 \mathrm{mg} / \mathrm{dL}$ & $357(80 \%)$ & $89(20 \%)$ & \multirow{2}{*}{$3.24(1.68-6.24)$} & \multirow{2}{*}{$<0.001$} \\
\hline & $<35 \mathrm{mg} / \mathrm{dL}$ & $143(93 \%)$ & $11(7 \%)$ & & \\
\hline \multirow[t]{2}{*}{ LDL } & $60-130 \mathrm{mg} / \mathrm{dL}$ & $293(80 \%)$ & $77(20 \%)$ & \multirow{2}{*}{$2.63(1.43-3.89)$} & \multirow{2}{*}{$<0.001$} \\
\hline & $>130 \mathrm{mg} / \mathrm{dL}$ & $207(90 \%)$ & $23(10 \%)$ & & \\
\hline Total & $\leq 1.1 \mathrm{mg} / \mathrm{dL}$ & $415(84 \%)$ & $81(16 \%)$ & \multirow{2}{*}{$0.87(0.50-1.51)$} & \multirow{2}{*}{0.63} \\
\hline Bilirubin & $>1.1 \mathrm{mg} / \mathrm{dL}$ & $85(82 \%)$ & $19(8 \%)$ & & \\
\hline \multirow{2}{*}{ ALT } & $\leq 42 \mathrm{IU} / \mathrm{L}$ & $389(84 \%)$ & $76(16 \%)$ & \multirow{2}{*}{$1.10(0.60-1.83)$} & \multirow{2}{*}{0.69} \\
\hline & $>42 \mathrm{IU} / \mathrm{L}$ & $111(82 \%)$ & $24(18 \%)$ & & \\
\hline \multirow{2}{*}{ AST } & $\leq 41 \mathrm{IU} / \mathrm{L}$ & $392(84 \%)$ & $75(16 \%)$ & \multirow{2}{*}{$1.21(0.73-1.99)$} & \multirow{2}{*}{0.45} \\
\hline & $>41 \mathrm{IU} / \mathrm{L}$ & $108(81 \%)$ & $25(19 \%)$ & & \\
\hline \multirow{2}{*}{ ALP } & $35-130 \mathrm{IU} / \mathrm{L}$ & $367(85 \%)$ & $64(15 \%)$ & \multirow{2}{*}{$1.55(0.98-2.44)$} & \multirow{2}{*}{0.058} \\
\hline & $>130 \mathrm{IU} / \mathrm{L}$ & $133(79 \%)$ & $36(21 \%)$ & & \\
\hline \multirow{2}{*}{ Serum Urea } & $10-50 \mathrm{mg} / \mathrm{dL}$ & $469(83 \%)$ & $93(17 \%)$ & \multirow{2}{*}{$1.13(0.48-2.66)$} & \multirow{2}{*}{0.76} \\
\hline & $>50 \mathrm{mg} / \mathrm{dL}$ & $31(82 \%)$ & $7(18 \%)$ & & \\
\hline \multirow{2}{*}{$\begin{array}{l}\text { Serum } \\
\text { Creatinine }\end{array}$} & $0.7-1.2 \mathrm{mg} / \mathrm{dL}$ & $452(83 \%)$ & $93(17 \%)$ & \multirow{2}{*}{$0.41(0.61-3.21)$} & \multirow{2}{*}{0.41} \\
\hline & $>1.2 \mathrm{mg} / \mathrm{dL}$ & $48(87 \%)$ & $7(13 \%)$ & & \\
\hline \multirow{2}{*}{$\begin{array}{l}\text { Serum } \\
\text { Acid }\end{array}$} & $3.4-7.0 \mathrm{mg} / \mathrm{dL}$ & $445(84 \%)$ & $84(16 \%)$ & \multirow{2}{*}{$1.54(0.84-2.81)$} & \multirow{2}{*}{0.16} \\
\hline & $>7.0 \mathrm{mg} / \mathrm{dL}$ & $55(77 \%)$ & $16(23 \%)$ & & \\
\hline
\end{tabular}

In this study family history of hypertension did not show any significant relation with the commencement of diabetes mellitus ( $\mathrm{p}$ value: 0.11 ; OR: 1.44 and $95 \%$ CI: 0.91-2.26). However, family history of diabetes mellitus is significantly associated with the incidence of diabetes mellitus ( $\mathrm{p}=0.002$, OR: $1.9795 \%$ CI: 1.27-3.04). Results presented in Table 4.

Table 4. Comparison of Family History of Diabetes and Hypertension among Diabetic and Non-Diabetic Group

\begin{tabular}{llllll}
\hline Characteristics & & $\begin{array}{l}\text { Diabetic } \\
\text { Group } \\
\mathrm{n}=500\end{array}$ & $\begin{array}{l}\text { Non-Diabetic } \\
\text { Group } \\
\mathrm{n}=100\end{array}$ & OR (95\% CI) & p value \\
\hline \multirow{2}{*}{ Family history of HTN } & Yes & $287(81 \%)$ & $66(19 \%)$ & $1.44(0.91-2.26)$ & 0.11 \\
& No & $213(86 \%)$ & $34(14 \%)$ & & 0.002 \\
\hline \multirow{2}{*}{ Family history of Diabetes } & Yes & $343(87 \%)$ & $52(13 \%)$ & $1.97(1.27-3.04)$ & \\
& No & $157(77 \%)$ & $48(23 \%)$ & & \\
\hline
\end{tabular}

\section{Discussion}

This study was designed to investigate the association of sociodemographic factors with the incidence of diabetes mellitus and to throw light on the relationship of diabetes mellitus with the lipid profile, liver function tests, and renal function tests. 
Results of this study suggest a high prevalence of diabetes in a local population of Lahore, Pakistan. It has been showed in the National diabetic survey conducted by Diabetes Association of Pakistan (DAP) and World Health Organization (WHO) that the prevalence of diabetes was 11\% in Pakistan in 1990s ("Milestones of the Diabetic Association of Pakistan," ; Sherin, 2015; World Health, 2016). According to International Diabetes Federation (IDF) report, the prevalence of diabetes in Pakistan in 2014 was approximately 7\% ("International Diabetes Federation ", 2015; Sherin, 2015). According to WHO and IDF reports 422 million adults have diabetes in 2014 and 415 million people had diabetes in 2015 respectively (IDF Diabetes Atlas, 2017; World Health, 2016). In this study, although the percentage of diabetes is much higher than previously reported. This study has strength that it reflects the association of not only social demographic characteristics but also laboratory parameters with family history of diabetes. However, there is some limitation as samples were collected from the specialized therapeutic clinic, which may a reason behind the high frequency of diabetes in our participants. The data of this was not randomly collected from population which is a limitation of this current study.

Findings of this study suggest that diabetes is more prevalent in adult age (mean age 49.05 years). Study of Dai et $a l$ in 2012 supported this fact that aging is an important risk factor for diabetes. Mitochondrial dysfunction starts with the aging, which disturbs the cellular physiology and helps in the development of pathological conditions like insulin resistance (D. F. Dai, 2012). The results of this study suggests that diabetes is prevalent in married people as compared to unmarried individuals, these results are in accordance with the earlier (Azimi-Nezhad et al., 2008; Corsi \& Subramanian, 2012)

Current findings suggest that smoking and alcohol are not significant for the onset of diabetes in accordance with the previous reports (Carter et al., 2015; Holmes et al., 2014; Mokdad et al., 2003).

Body mass index (BMI) is significantly associated with the commencement of diabetes mellitus. Multi-various studies showed the positive connection of high BMI with the diabetes mellitus. Overweight/obesity contribute to fatty liver or insulin resistance and also disturbs body metabolism thus helps in the progression of diabetes (Sung, Jeong, Wild, \& Byrne, 2012). Modern lifestyle, physical inactivity or psychological stress are the causes of abnormal BMI which leads to diabetes mellitus. Studies showed that there are $42 \%$ more risk for diabetes if BMI of a person is above 30 .

It was also observed that Type 2 diabetes mellitus is the most prevalent type of diabetes among others. Dey et al in 2011 reported that $5-10 \%$ cases are suffering from Type 1 diabetes while $90-95 \%$ cases are of Type 2 diabetes mellitus (Dey \& Attele, 2011). This high prevalence of Type 2 diabetes may be due to psychological behavior, hypertension, stress, obesity, moderate lifestyle with less physical activities and improper glycemic control. All these factors considered as risk factors for the diabetes mellitus (Sethi et al., 2011).

We reported a significant association of Lipid profile (Cholesterol, triglyceride, HDL and LDL) with diabetes. Results indicate Cholesterol, Triglyceride, and LDL were elevated whereas HDL which is considered as a good cholesterol was less in diabetic patients. Our results are consistent with previous reports (Khan, Sobki, \& Khan, 2007; Meikle et al., 2013) those suggested hypercholesterolemia, hypertriglyceridemia, high LDL and low HDL levels are the significant risk factors for the cardiovascular disorders in diabetic patients (VinodMahato et al., 2011) and $8 \%$ of diabetic patients of this study have diabetic lipidus. In the study of Pandya et al, $82 \%$ of diabetic patients showed dyslipidemia (Pandya, Lakhani, Dadhania, \& Trivedi, 2012). Major etiology behind diabetic lipidus is insulin resistance due to the interaction of insulin with apolipoproteins and adipocytes in obesity (Meikle, Wong, Barlow, \& Kingwell, 2014). Dyslipidemia together with diabetes mellitus is the leading cause of Ischemic heart disease (IHD) as indicated by the prevalence of IDH in diabetic patients of the current study is $6 \%$.

In contrast to previous studies our results did not suggest any association of Liver enzymes (ALT, AST, and ALP) with diabetes (Harris, 2005; Nannipieri et al., 2005; Vozarova et al., 2002).Liver enzymes are not directly linked with diabetes however abnormal liver enzymes may be due to obesity or any other complication that arise after diabetes. Similarly in our samples renal function test also did not show any statistical significant association with diabetes.

Bamanikar et al concluded that serum urea and serum creatinine are the predictors of the nephropathy in diabetic patients (Bamanikar, Bamanikar, \& Arora, 2016). Though mostly studies reported that renal function tests are associated with diabetes, the reason behind the results of this current study may be a short duration of diabetes onset, as nephropathy occurs after the prognosis of diabetes.

Uric acid is the metabolic end product of purines their levels raised in nephropathies. The current finding is supported by the results of Bandaru and Taniguchi they found a negative association between serum uric acid and diabetes while contradicted by others (Bandaru \& Shankar, 2011; Kodama et al., 2009; Kramer, Von Mühlen, 
Jassal, \& Barrett-Connor, 2009; Taniguchi et al., 2001). Results of this study also showed that prevalence of nephropathy in diabetic patients is $5 \%$.

Though studies have reported that there is a significant relationship between prognosis of diabetes and nephropathy. Studies have also revealed that presence of HTN in diabetic patients also trigger this relationship. Results of our study did not show any significance association between diabetes and nephropathy. So we further examined the relationship between hypertension and RFTs.

A high prevalence of hypertension in diabetic patients in contrast to other complications was also observed in this study. Increased body mass index is the main reason behind high prevalence of hypertension, as this study has indicated a high prevalence of increased BMI in diabetic patients. Colosia et al, in 2013 reported hypertension with or without obesity is very much prevalent in diabetic patients (Colosia, Palencia, \& Khan, 2013). Other studies showed same results in Romania and Japan (Dorobantu, Darabont, Badila, \& Ghiorghe, 2010; Nakano et al., 2004). Blood glucose damages the arteries and makes them hard (atherosclerosis), result in the high blood pressure and cardiovascular disorders.

The family history of diabetes was observed as a significant factor in the onset of diabetes. A person has $1.97 \%$ more chances if first degree relatives have a positive history of diabetes as showed in this study. The family history of diabetes and hypertension is important in the individuals with metabolic syndrome for the commencement of Type 2 diabetes mellitus (Das, Pal, \& Ghosh, 2012; Ranasinghe, Cooray, Jayawardena, \& Katulanda, 2015). Family history of diabetes is an independent risk factor for diabetes in the Local Population of Lahore, as reported in the study of Zafar et al, in 2013 (Zafar, Qureshi, \& Sandhu).

Diabetic individuals are at high risk for developing complications like cardiovascular disease, nephropathy, neuropathy, retinopathy, dyslipidemia, diabetic foot, infectious diseases, and pregnancy complications (IDF Diabetes Atlas, 2017). Deshpande et al in 2008 also reported high prevalence of complications in diabetic patients (Deshpande, Harris-Hayes, \& Schootman, 2008). There is no exact estimation of complication in diabetic patients, but many studies showed the prevalence of individual complication of diabetes.

\section{Conclusion}

Type 2 Diabetes Mellitus is highly prevalent in the local population of Lahore, Pakistan. Family history along with other risk factors like high Cholesterol, Triglyceride, Body Mass Index (BMI $>25)$ and low High-Density lipoproteins (HDL) contributes to the development of diabetes. An improved lifestyle and medical monitoring can manage to control diabetes in the local population. Further studies with a large cohort and to evaluate genetic risk factors are required in this population.

\section{Competing Interests Statement}

The authors declare that there are no competing or potential conflicts of interest.

\section{Author's Contribution}

SA perform lab work and draft this manuscript, ST, BT design this study and did sampling, NT, TR, SM and AM recruitment of patients and lab work, KJ design this study, statistical analysis and final revision of the manuscript.

\section{References}

Azimi-Nezhad, M., Ghayour-Mobarhan, Mpmr, Parizadeh, M. R., Safarian, M., Esmaeili, H., Parizadeh, S. M. J., . . Hassankhani, B. (2008). Prevalence of type 2 diabetes mellitus in Iran and its relationship with gender, urbanisation, education, marital status and occupation. Singapore Medical Journal, 49(7), 571.

Bamanikar, S. A., Bamanikar, A. A., \& Arora, A. (2016). Study of Serum urea and Creatinine in Diabetic and non-diabetic patients in in a tertiary teaching hospital. Journal of Medical Research, 2(1), 12-15.

Bandaru, Pavani, \& Shankar, Anoop. (2011). Association between serum uric acid levels and diabetes mellitus. International Journal of Endocrinology, 2011. https://doi.org/10.1155/2011/604715

Carter, B. D., Abnet, C. C., Feskanich, D., Freedman, N. D., Hartge, P., Lewis, C. E., . . Thun, M. J. (2015). Smoking and mortality—-beyond established causes. New England Journal of Medicine, 372(7), 631-640. https://doi.org/10.1056/NEJMsa1407211

Colosia, A. D., Palencia, R., \& Khan, S. (2013). Prevalence of hypertension and obesity in patients with type 2 diabetes mellitus in observational studies: a systematic literature review. Diabetes Metabolic Syndrome Obesity, 6(1), 327-338. https://doi.org/10.2147/DMSO.S51325 
Corsi, D. J., \& Subramanian, S. V. (2012). Association between socioeconomic status and self-reported diabetes in India: a cross-sectional multilevel analysis. BMJ Open, 2(4). https://doi.org/10.1136/bmjopen-2012-000895

Dai, D. F., Rabinovitch, P. S., \& Ungvari, Z. (2012). Mitochondria and cardiovascular aging. PubMed Central, 110(8), 1109-1124. https://doi.org/10.1161/circresaha.111.246140

Das, M., Pal, S., \& Ghosh, A. (2012). Family history of type 2 diabetes and prevalence of metabolic syndrome in adult Asian Indians. Journal of Cardiovascular Disease Research, 3(2), 104-108. https://doi.org/10.4103/0975-3583.95362

Deshpande, A. D., Harris-Hayes, M., \& Schootman, M. (2008). Epidemiology of diabetes and diabetes-related complications. Physical Therapy, 88(11), 1254. https://doi.org/10.2522/ptj.20080020

Dey, L., \& Attele, A. S. (2011). Type 2 diabetes. Tradit Chinese Med, 231(1), 1-16.

Dorobantu, M., Darabont, R. O., Badila, E., \& Ghiorghe, S. (2010). Prevalence, awareness, treatment, and control of hypertension in Romania: results of the SEPHAR Study. International Journal of Hypertension, 2010. https://doi.org/10.4061/2010/970694

Harris, E. H. (2005). Elevated Liver Function Tests in Type 2 Diabetes. Clinical Diabetes, 23(3), $115-119$. https://doi.org/10.2337/diaclin.23.3.115

Holmes, M. V., Dale, C. E., Zuccolo, L., Silverwood, R. J., Guo, Y., Ye, Z., . . . Wong, A. (2014). Association between alcohol and cardiovascular disease: Mendelian randomisation analysis based on individual participant data. BMJ, 349, g4164. https://doi.org/10.1136/bmj.g4164

IDF Diabetes Atlas. (2017). (7th ed.): International Diabetes Federation.

International Diabetes Federation (2015). from http://www.idf.org/membership/mena/

Khan, H. A., Sobki, S. H., \& Khan, S. A. (2007). Association between glycaemic control and serum lipids profile in type 2 diabetic patients: HbA1c predicts dyslipidaemia. Clinical And Experimental Medicine, 7(1), 24-29. https://doi.org/10.1007/s10238-007-0121-3

Kodama, S., Saito, K., Yachi, Y., Asumi, M., Sugawara, A., Totsuka, K., . . Sone, H. (2009). Association between serum uric acid and development of type 2 diabetes. Diabetes Care, 32(9), 1737-1742. https://doi.org/10.2337/dc09-0288

Kramer, C. K., Von Mühlen, D., Jassal, S. K., \& Barrett-Connor, E. (2009). Serum uric acid levels improve prediction of incident Type 2 Diabetes in individuals with impaired fasting glucose. Diabetes Care, 32(7), 1272-1273. https://doi.org/10.2337/dc09-0275

Leech, C. A., Dzhura, I., Chepurny, O. G., Kang, G., Schwede, F., Genieser, H.- G., \& Holz, G. G. (2011). Molecular physiology of glucagon-like peptide- 1 insulin secretagogue action in pancreatic $\beta$ cells. Progress In Biophysics And Molecular Biology, 107(2), 236-247. https://doi.org/10.1016/j.pbiomolbio.2011.07.005

Malandrino, N., Wu, W. C., Taveira, T. H., Whitlatch, H. B., \& Smith, R. J. (2012). Association between red blood cell distribution width and macrovascular and microvascular complications in diabetes. Diabetologia, 55(1), 226-235. https://doi.org/10.1007/s00125-011-2331-1

Meikle, P. J., Wong, G., Barlow, C. K., \& Kingwell, B. A. (2014). Lipidomics: potential role in risk prediction and therapeutic monitoring for diabetes and cardiovascular disease. Pharmacology And Therapeutics, 143(1), 12-23. https://doi.org/10.1016/j.pharmthera.2014.02.001

Meikle, P. J., Wong, G., Barlow, C. K., Weir, J. M., Greeve, M. A., MacIntosh, G. L., . . Kowalczyk, A. (2013). Plasma lipid profiling shows similar associations with prediabetes and type 2 diabetes. PloS One, 8(9), e74341. https://doi.org/10.1371/journal.pone.0074341

Milestones of the Diabetic Association of Pakistan.).Retrieved from http://www.dap.org. pk/default.html

Model, C. C. (2015). Standards of medical care in diabetes-2015 abridged for primary care providers. Diabetes Care, $38(1), \mathrm{S} 1-\mathrm{S} 94$.

Mokdad, A. H., Ford, E. S., Bowman, B. A., Dietz, W. H., Vinicor, F., Bales, V. S., \& Marks, J. S. (2003). Prevalence of obesity, diabetes, and obesity-related health risk factors, 2001. Jama, 289(1), 76-79. https://doi.org/10.1001/jama.289.1.76

Nakano, Shigeru, Tomohiko, I. T. O., Furuya, Keisuke, Tsuda, Shin-ichi, Konishi, Kazunori, Nishizawa, Makoto, . . . Uchida, Kenzo. (2004). Ambulatory blood pressure level rather than dipper/nondipper status 
predicts vascular events in type 2 diabetic subjects. Hypertension Research, 27(9), 647-656. https://doi.org/10.1291/hypres.27.647

Nannipieri, M., Gonzales, C., Baldi, S., Posadas, R., Williams, K., Haffner, S. M., . . Ferrannini, E. (2005). Liver Enzymes, the Metabolic Syndrome, and Incident Diabetes. The Mexico City Diabetes Study, 28(7), 1757-1762. https://doi.org/10.2337/diacare.28.7.1757

Pandya, Hetal, Lakhani, J. D., Dadhania, J., \& Trivedi, A. (2012). The Prevalence and Pattern of Dyslipidemia among Type 2 Diabetic Patients at Rural Based Hospital in Gujarat, India. Indian Journal of Clinical Practice, 22(12), 640-648.

Ranasinghe, P., Cooray, D. N., Jayawardena, R., \& Katulanda, P. (2015). The influence of family history of hypertension on disease prevalence and associated metabolic risk factors among Sri Lankan adults. BMC Public Health, 15(1), 576. https://doi.org/10.1186/s12889-015-1927-7

Sethi, Surbhi, Kumar, Parvinder, Gupta, Subash, \& Bhanwer, A. J. S. (2011). Study of risk factors for the high prevalence of type 2 diabetes in the people of Jammu. Journal of Human Ecology, 36(3), 217-221.

Sherin, Akhtar. (2015). National Diabetes Action Plan Of Pakistan: Need And Challenges. Khyber Medical University Journal, 7(1), 1-2.

Sung, K.-C., Jeong, W.-S., Wild, S. H., \& Byrne, C. D. (2012). Combined Influence of Insulin Resistance, Overweight/Obesity, and Fatty Liver as Risk Factors for Type 2 Diabetes. Diabetes Care, 35(4), 717-722. https://doi.org/10.2337/dc11-1853

Taniguchi, Y., Hayashi, T., Tsumura, K., Endo, G., Fujii, S., \& Okada, K. (2001). Serum uric acid and the risk for hypertension and Type 2 diabetes in Japanese men: The Osaka Health Survey. Journal of Hypertension, 19(7), 1209-1215. https://doi.org/10.1097/00004872-200107000-00005

VinodMahato, R., Gyawali, P., Raut, P. P., Regmi, P., Singh, K. P., Pandeya, D. R., \& Gyawali, P. (2011). Association between glycaemic control and serum lipid profile in type 2 diabetic patients: Glycated haemoglobin as a dual biomarker. Biomedical Research.

Vozarova, B., Stefan, N., Lindsay, R. S., Saremi, A., Pratley, R. E., Bogardus, C., \& Tataranni, P. A. (2002). High alanine aminotransferase is associated with decreased hepatic insulin sensitivity and predicts the development of type 2 diabetes. Diabetes, 51(6), 1889-1895. https://doi.org/10.2337/diabetes.51.6.1889

World Health, Organization. (2016). Global report on diabetes.

Zafar, U., Qureshi, H. J., \& Sandhu, Q. S. (n.d.). Frequency and Association of Family History of Type 2 Diabetes in Type 2 Diabetic Patients.

Zimmet, P. Z., Magliano, D. J., Herman, W. H., \& Shaw, J. E. (2014). Diabetes: a 21st century challenge. The Lancet Diabetes \& Endocrinology, 2(1), 56-64. https://doi.org/10.1016/S2213-8587(13)70112-8

\section{Copyrights}

Copyright for this article is retained by the author(s), with first publication rights granted to the journal.

This is an open-access article distributed under the terms and conditions of the Creative Commons Attribution license (http://creativecommons.org/licenses/by/4.0/). 